\title{
Maternal body size and birth weight: can insulin or adipokines do better?
}

\author{
Johan Verhaeghe, ${ }^{\mathrm{a}, *}$, Rita van Bree ${ }^{\mathrm{a}}$, Erik Van Herck ${ }^{\mathrm{b}}$ \\ ${ }^{a}$ Department of Obstetrics and Gynecology, Katholieke Universiteit Leuven, 3000 Leuven, Belgium \\ ${ }^{\mathrm{b}}$ Laboratorium voor Experimentele Geneeskunde en Endocrinologie, Katholieke Universiteit Leuven, 3000 Leuven, Belgium
}

Received 16 March 2005; accepted 9 September 2005

\begin{abstract}
Overweight gravidas and gravidas with a robust weight gain have an accrued risk of delivering a large-for-gestational age (LGA) baby. Here, we examined whether the measurement of insulin and adipokines - peptides secreted mainly by adipose tissue - at the glucose challenge test (GCT) improves the prediction of birth weight. We studied 631 singleton pregnancies at 24 to 29 weeks' gestational age (GA) with data on height, baseline body weight (BW), and BW change between baseline and the GCT. In addition to glucose and insulin, we measured adiponectin, leptin, soluble leptin receptor (the main leptin-binding protein), and tumor necrosis factor $\alpha$. We found that birth weight was related to maternal height, baseline BW, and BW change, and also - albeit less strongly - to insulin, adiponectin, leptin, and soluble leptin receptor concentrations. In multiple regression analyses, body size parameters explained $\sim 10 \%$ of the variance in birth weight, of which BW change was the most important correlate, but the metabolic markers added only 2\% variance, with leptin alone adding $1.4 \%$. Gravidas carrying a small-for-GA (SGA) fetus were more likely to have a leptin value in the highest quartile than those with an appropriatefor-GA fetus (odds ratio, 2.6; 95\% confidence interval, 1.1-6.3; $P=.04$ ), but there were no other differences in the metabolic markers between SGA or LGA and appropriate-for-GA pregnancies. In conclusion, measuring insulin and adipokines at the GCT has limited, if any, clinical benefit to predict which fetuses will be SGA or LGA at birth.
\end{abstract}

(C) 2006 Elsevier Inc. All rights reserved.

\section{Introduction}

Extensive evidence indicates that maternal prepregnancy body weight (BW), or BW at the first antenatal visit, correlates with birth weight [1]. In addition, excessive gestational BW gain puts gravidas at risk for delivering a large-for-gestational age (LGA) baby (ie, with birth weight above the 90th percentile $\left[>\mathrm{P}_{90}\right]$ ), whereas $\mathrm{BW}$ gain is inversely and linearly related to the incidence of small-forgestational-age (SGA) babies $\left(\leq \mathrm{P}_{10}\right)$ [2]. To optimize pregnancy outcome, the US Institute of Medicine proposed recommendations on gestational BW gain depending on the prepregnancy body mass index (BMI) [3].

Body weight and $\mathrm{BW}$ change are regulated by insulin and adipokines such as leptin, adiponectin, and tumor necrosis factor $\alpha(\mathrm{TNF}-\alpha)$. Adipokines are secreted mainly but not exclusively by adipose tissue; during pregnancy, they are also secreted by the placenta. Insulin and leptin

\footnotetext{
* Corresponding author. Tel.: +32 16344212; fax: +32 16344205 .
}

E-mail address: johan.verhaeghe@uz.kuleuven.ac.be (J. Verhaeghe). modulate energy intake and expenditure via central pathways [4]; plasma insulin and leptin are correlated with BMI in nonpregnant and pregnant [5] individuals. Circulating leptin is bound to a large extent to the soluble form of the leptin receptor (sOb-R); sOb-R levels are inversely related to BMI, fat mass, and circulating leptin $[5,6]$. Plasma insulin [7], leptin [8], and sOb-R [9] concentrations are raised during pregnancy, but there is no change in the free leptin fraction [9]. Circulating adiponectin is inversely related to fat mass, and adiponectin is thought to be an important link between excess fat and insulin resistance [10]. Finally, the rise in TNF- $\alpha$ during pregnancy has been related to the pregnancy-associated insulin resistance [11].

The relationship between maternal insulin/adipokines and birth weight is controversial. Birth weight was inversely related to the insulin concentrations during an oral glucose tolerance test performed around 27 weeks' gestational age (GA) in nondiabetic gravidas [12]; but in another study, birth weight was inversely correlated with maternal insulin sensitivity in late pregnancy [13]. And although a robust leptin surge during pregnancy was 
associated with an elevated risk of low birth weight in one study [14], we failed to confirm a relationship between maternal leptin concentrations at 24 to 29 weeks' GA and birth weight percentile [15].

The glucose challenge test (GCT) is a screening test for gestational diabetes mellitus (GDM) performed in the large majority of pregnancies [16] at an appropriate time to assess the metabolic adjustments to pregnancy. The threshold value for an abnormal GCT is $7.8 \mathrm{mmol} / \mathrm{L}$ (sensitivity, $80 \%$ ) or $7.2 \mathrm{mmol} / \mathrm{L}$ (sensitivity, 90\%) [16]. Discussing the rationale of the GCT with their patients, clinicians often refer to the screening of fetal macrosomia. Herein, we examined whether the measurement of insulin or adipokines at the GCT adds meaningfully to the prediction of birth weight.

\section{Materials and methods}

\subsection{Study design and subjects}

The protocol was approved by the Ethical Committee of the KUL Faculty of Medicine. This study was a nested cohort study within the Leuven GCT study, carried out between December 2001 and June 2003. In this study, 800 white Belgian (or Dutch) women, pregnant with a single fetus, donated an extra blood sample for the purpose of this study at the time of their GCT (between 24 and 29 weeks' GA) prescribed by their OB/GYN physician. The population was unselected for risk factors of GDM [17], but none of the women had known glucose intolerance or diabetes. A venous blood sample was performed 60 minutes after drinking $100 \mathrm{~mL}$ of a $50 \%$ glucose solution; in the meantime, subjects were requested not to eat, drink, chew gum, or smoke, and not to walk about. Glucose challenge tests occurred throughout the day (between $9 \mathrm{AM}$ and $8 \mathrm{PM}$ ), in the fasting or (in the large majority) nonfasting state. Samples were kept at $4^{\circ} \mathrm{C}$, centrifuged on a twice-daily basis, aliquoted, and stored at $-80^{\circ} \mathrm{C}$.

Clinical data were retrieved from the patient files. Body weight was measured to the nearest $0.1 \mathrm{~kg}$ value on a digital scale at each antenatal visit, and height was measured to the nearest centimeter at the first visit, by staff nurses. However, we found no recorded height measurement for 8 subjects and no BW measurement at the GCT for 11 subjects; they were excluded from the study. In addition, we excluded 150 gravidas with the first visit at or later than 15 weeks' $\mathrm{GA}$, so as to ensure that the minimum period between baseline and the GCT would be 10 weeks. Hence, the final sample consisted of 631 gravidas who booked between 5 and 14 weeks' GA (mean, 10.4 weeks) and had complete data on height, BW at baseline, and BW at the GCT (Table 1). The smoking status was assessed at baseline. Hypertension was defined and classified as previously proposed [18]: 31 of the 631 women had chronic (preexisting) hypertension, 88 developed hypertension in the second half of pregnancy (gestational hypertension), and 6 developed preeclampsia. The birth weight SD score was
Table 1

Sample characteristics $(\mathrm{N}=631)$

\begin{tabular}{lc}
\hline & Median (range) \\
\hline Age $(\mathrm{y})$ & $30(18-43)$ \\
Height $(\mathrm{cm})$ & $167(148-186)$ \\
Baseline BW $(\mathrm{kg})$ & $63.8(40.4-118.5)$ \\
Baseline BMI $\left(\mathrm{kg} / \mathrm{m}^{2}\right)$ & $23.7(16.4-44.2)$ \\
BW change from baseline to GCT $(\mathrm{kg})$ & $7.2(-3.1$ to +18.6$)$ \\
Plasma glucose at GCT (mmol/L) & $6.2(3.2-13.3)$ \\
Insulin $(\mathrm{pmol} / \mathrm{L})$ & $617(47-4686)$ \\
Adiponectin $(\mathrm{nmol} / \mathrm{L})$ & $0.49(0.07-2.83)$ \\
Leptin $(\mathrm{nmol} / \mathrm{L})$ & $1.09(0.15-4.82)$ \\
sOb-R $(\mathrm{U} / \mathrm{mL})(\mathrm{n}=629)$ & $35.8(4.3-113.3)$ \\
TNF- $\alpha(\mathrm{pg} / \mathrm{mL})(\mathrm{n}=584)$ & $2.76(0.90-30.45)$ \\
Time between GCT and delivery (wk) & $13(3-17)$ \\
GA at delivery $(\mathrm{wk})$ & $39(30-41)$ \\
Birth weight $(\mathrm{g})$ & $3420(1450-5250)$ \\
Birth weight SD score & $0.157(-2.981-3.883)$ \\
& \\
Parity at baseline $(0 / 1 / 2 />2)$ & Frequency \\
Smoking at baseline (no/yes) & $309(49.0 \%) / 218 / 81 / 23$ \\
Post-GCT glucose $<7.2$ mmol/L (yes/no) & $579(91.8 \%) / 52$ \\
Hypertension during pregnancy (no/yes) & $473(75.0 \%) / 158$ \\
Fetal sex (female/male) & $506(80.2 \%) / 125$ \\
\hline
\end{tabular}

computed from Flemish BW charts derived from more than 429000 births; the percentile groups (SGA, appropriatefor-GA [AGA], and LGA) were stratified from the same database [19].

\subsection{Plasma assays}

Glucose was measured by the glucose oxidase method with a YSI 2300 Stat Plus glucometer (YSI, Yellow Springs, $\mathrm{OH})$, which was calibrated before each assay; within-assay coefficient of variation $(\mathrm{CV})$ is $1.2 \%$. Insulin was measured by radioimmunoassay, with recombinant human insulin as the standard, and a rabbit polyclonal antiserum; the detection limit is $15 \mathrm{pmol} / \mathrm{L}(2.5 \mu \mathrm{U} / \mathrm{mL})$, and within- and between-assay $\mathrm{CV}$ is less than $6.0 \%$ [15]. Adiponectin and leptin were measured by radioimmunoassay with recombinant adiponectin and leptin as the standard, respectively, and a rabbit polyclonal antiserum (Linco Research, St Charles, $\mathrm{MO})$. For the adiponectin assay, the detection limit is $1 \mathrm{ng} / \mathrm{mL}(33.3 \mathrm{pmol} / \mathrm{L})$, and within- and between-assay CV is less than $9.3 \%$. For the leptin assay, detection limit is $0.5 \mathrm{ng} / \mathrm{mL}(0.031 \mathrm{nmol} / \mathrm{L})$, and within- and between-assay $\mathrm{CV}$ is less than $8.4 \%$. Soluble leptin receptor was measured by enzyme immunoassay using a monoclonal antihuman leptin receptor antibody (BioVendor Laboratory Medicine, Brno, Czech Republic); the detection limit is $0.4 \mathrm{U} / \mathrm{mL}$, and between- and within-assay CV is less than $6.4 \%$. Tumor necrosis factor $\alpha$ was assayed with enzyme immunoassay using recombinant TNF- $\alpha$ as the standard and both a monoclonal and polyclonal antibody (Quantikine High Sensitivity, R\&D Systems, Abingdon, UK); the detection limit is $0.12 \mathrm{pg} / \mathrm{mL}$, within-assay $\mathrm{CV}$ is $5.3 \%$ to $8.8 \%$ and between-assay CV is $10.8 \%$ to $16.7 \%$. 
Table 2

Pearson correlations between maternal body size and metabolic parameters $(\mathrm{N}=631)$

\begin{tabular}{llrrc}
\hline & Height & $\begin{array}{l}\text { Baseline } \\
\text { BW }\end{array}$ & $\begin{array}{l}\text { Baseline } \\
\text { BMI }\end{array}$ & $\begin{array}{l}\text { BW change } \\
\text { to GCT }\end{array}$ \\
\hline Glucose & $-0.129^{* *}$ & $0.129^{* *}$ & $0.191^{* * *}$ & NS \\
Insulin & $-0.121^{* *}$ & $0.231^{* * *}$ & $0.294^{* * *}$ & $0.108^{* *}$ \\
Adiponectin & $\mathrm{NS}$ & $-0.258^{* * *}$ & $-0.254^{* * *}$ & $\mathrm{NS}$ \\
Leptin & $\mathrm{NS}$ & $0.528^{* * *}$ & $0.571^{* * *}$ & $0.190^{* * *}$ \\
sOb-R & $0.084^{*}$ & $-0.442^{* * *}$ & $-0.493^{* * *}$ & $-0.117^{* *}$ \\
Free leptin index & $-0.086^{*}$ & $0.476^{* * *}$ & $0.529^{* * *}$ & $0.125^{* *}$ \\
TNF- $\alpha$ & $\mathrm{NS}$ & $\mathrm{NS}$ & $\mathrm{NS}$ & $\mathrm{NS}$ \\
\hline
\end{tabular}

Baseline BW, baseline BMI, glucose, insulin, adiponectin, leptin, sOb-R, and TNF- $\alpha$ data were not normally distributed; therefore, we used logtransformed values to obtain normal data distribution or improved normality of data distribution. NS indicates not significant $(P>.05)$.

$* P<.05$ (pairwise correlations).

** $P<.01$ (pairwise correlations).

*** $P<.001$ (pairwise correlations).

\subsection{Data analysis}

We used the NCSS software version 2004 (Kaysville, UT). The free leptin index was calculated as the leptinsOb-R ratio. The normality of data distribution was checked by the D'Agostino-Omnibus test; if not normally distributed, we $\log$ transformed the data. Correlation matrices were examined using Pearson pairwise correlation coefficients. Other procedures were $\chi^{2}$ tests; 1 -way analysis of variance, followed, if $P<.05$, by Tukey-Kramer multiplecomparison test to examine intergroup differences; robust multiple regression according to Huber; and multinomial logistic regression.

\section{Results}

Table 1 presents the medians (ranges) of the metabolic markers. We assessed by 1-way analysis of variance whether the metabolic parameters were related to GA at blood sampling (24-29 weeks): there was no such effect for glucose $(P=.31)$, insulin $(P=.15)$, adiponectin $(P=.33)$, leptin $(P=.90)$, the free leptin index $(P=.12)$, or TNF- $\alpha(P=.41)$. There was a slight GA-related difference in sOb-R levels $(P=.048)$, with a significant difference between 25 and 26 weeks' GA by Tukey-Kramer post hoc test; however, GA at sampling and sOb-R levels were not significantly correlated (Pearson correlation coefficient $[r]=0.051, P=.20$ ).

Table 2 shows the correlations between maternal body size and metabolic parameters. Baseline BW and BMI were related to post-GCT glucose, insulin, total and free leptin (positively), and adiponectin and sOb-R (negatively); height was related to sOb-R and inversely related to glucose and insulin. Body weight change from baseline to GCT was inversely related to baseline BW $(r=-0.140, P<.0001)$, yet was correlated with insulin, leptin, and sOb-R at the GCT, if to a smaller extent, than were baseline BW and BMI. Insulin was correlated with glucose $(r=0.516)$, adiponectin $(r=-0.253)$, leptin $(r=0.378)$, sOb-R $(r=-0.287)$, free leptin index $(r=0.331)$ (all $P<.0001)$, and TNF- $\alpha(r=0.112, P=.007)$; leptin was inversely correlated with sOb-R $(r=-0.566)$ and adiponectin $(r=-0.204)$ (both $P<.0001)$.

In Table 3, we demonstrate that maternal body size parameters were correlated with birth weight controlled for GA, sex, and maternal parameters (parity, smoking, and hypertension); because maternal age was not correlated with birth weight ( $r=0.06, P=.13$ ), age was not included as a controlling variable. From the metabolic variables, insulin, adiponectin, leptin, and sOb-R concentrations were related to birth weight, with sOb-R as the most significant metabolic correlate.

Multiple regression analyses are presented in Table 4 . We show the analysis for the whole group and for the subgroups of gravidas with a normal GCT and those who were overweight at baseline. Body weight change emerged as the most important body size parameter and plasma leptin as the most important metabolic marker; however, plasma leptin added only $1.4 \%$ to the variance in birth weight. There was no multicollinearity between the independent variables (data not shown). The multiple regression analysis was also comparable in the subgroups of term pregnancies, and in normotensive or nonsmoking gravidas (data not shown).

Table 5 shows the logistic regression analyses in SGA vs AGA and LGA vs AGA pregnancies (dependent variable) and the same independent variables as in Table 4. Compared with the gravidas carrying an AGA fetus, SGA gravidas were more likely to be smokers, nulliparous, and to be pregnant with a girl; they were also about 4 times less likely to gain more than $7.2 \mathrm{~kg}$ from baseline to the GCT. Smallfor-GA gravidas were not more likely to have any metabolic marker value above vs below the median. However, in a

Table 3

Pearson correlations between birth weight and maternal body size/ metabolic parameters $(\mathrm{N}=631)$

\begin{tabular}{|c|c|c|}
\hline Controlling variables & $\mathrm{GA}, \operatorname{sex}(P)$ & $\begin{array}{l}\text { GA, sex }+ \text { materna } \\
\text { variables }(P)^{\mathrm{a}}\end{array}$ \\
\hline \multicolumn{3}{|l|}{ Body size parameters } \\
\hline Height & $0.182(<.0001)$ & $0.186(<.0001)$ \\
\hline $\mathrm{BW}$ at baseline $\mathrm{e}^{\mathrm{b}}$ & $0.208(<.0001)$ & $0.241(<.0001)$ \\
\hline BMI at baseline ${ }^{b}$ & $0.129(.001)$ & $0.159(<.0001)$ \\
\hline $\begin{array}{l}\text { BW change from } \\
\text { baseline to GCT }\end{array}$ & $0.172(<.0001)$ & $0.214(<.0001)$ \\
\hline \multicolumn{3}{|l|}{ Metabolic markers at GCT } \\
\hline Glucose $^{\mathrm{b}}$ & $0.071(.077)$ & $0.063(.12)$ \\
\hline Insulin ${ }^{\mathrm{b}}$ & $0.070(.078)$ & $0.094(.018)$ \\
\hline Adiponectin $^{\mathrm{b}}$ & $-0.085(.034)$ & $-0.095(.018)$ \\
\hline Leptin ${ }^{b}$ & $0.032(.42)$ & $0.081(.043)$ \\
\hline $\mathrm{sOb}-\mathrm{R}^{\mathrm{b}}(\mathrm{n}=629)$ & $-0.148(.0002)$ & $-0.174(<.0001)$ \\
\hline Free leptin index $(\mathrm{n}=629)$ & $0.095(.022)$ & $0.121(.004)$ \\
\hline $\mathrm{TNF}-\alpha^{\mathrm{b}}(\mathrm{n}=584)$ & $-0.049(.24)$ & $-0.049(.24)$ \\
\hline
\end{tabular}

${ }^{a}$ Maternal variables: parity, smoking, hypertension.

${ }^{b}$ We used log-transformed values to obtain normal data distribution or improved normality of data distribution. 
Table 4

Clinical and metabolic correlates of birth weight: multiple regression analysis (robust regression using the method of Huber)

\begin{tabular}{|c|c|c|c|c|c|c|c|c|c|}
\hline \multirow[t]{2}{*}{ Dependent variable: birth weight } & \multicolumn{3}{|c|}{ Total group $(\mathrm{n}=629)$} & \multicolumn{3}{|c|}{ Normal GCT $(<7.2 \mathrm{mmol} / \mathrm{L})(\mathrm{n}=472)$} & \multicolumn{3}{|c|}{ Baseline BMI $\geq 25 \mathrm{~kg} / \mathrm{m}^{2}(\mathrm{n}=229)$} \\
\hline & $T^{\mathrm{a}}$ & $R^{2}$ & $P$ & $T^{\mathrm{a}}$ & $R^{2}$ & $P$ & $T^{\mathrm{a}}$ & $R^{2}$ & $P$ \\
\hline \multicolumn{10}{|l|}{ Independent variables } \\
\hline \multicolumn{10}{|l|}{ General parameters } \\
\hline Gestational age & 20.58 & $36.41^{\mathrm{b}}$ & $<.0001$ & 16.87 & $35.16^{\mathrm{b}}$ & $<.0001$ & 12.29 & $37.99^{\mathrm{b}}$ & $<.0001$ \\
\hline Sex (female vs male) & -7.01 & 3.57 & $<.0001$ & -6.15 & 3.66 & $<.0001$ & -3.67 & 3.16 & .0003 \\
\hline Parity & 5.56 & 3.31 & $<.0001$ & 5.01 & 3.84 & $<.0001$ & 2.94 & 0.91 & .004 \\
\hline Smoking (yes vs no) & -5.51 & 1.64 & $<.0001$ & -4.26 & 1.43 & $<.0001$ & -3.08 & 0.92 & .002 \\
\hline Hypertension (yes vs no) & -4.05 & 0.42 & .0001 & -2.62 & 0.24 & .009 & -1.80 & 0.17 & .074 \\
\hline \multicolumn{10}{|l|}{ Maternal body size parameters } \\
\hline Baseline $\mathrm{BW}^{\mathrm{c}}$ & 5.52 & 2.92 & $<.0001$ & 4.85 & 3.16 & $<.0001$ & 2.66 & 1.48 & .008 \\
\hline BW change to GCT & 7.48 & 4.37 & $<.0001$ & 6.60 & 4.66 & $<.0001$ & 6.03 & 8.82 & $<.0001$ \\
\hline Height & 1.94 & 0.39 & .053 & 2.00 & 0.63 & .047 & 2.19 & 1.30 & .029 \\
\hline \multicolumn{10}{|l|}{ Maternal metabolic markers } \\
\hline $\mathrm{sOb}-\mathrm{R}^{\mathrm{c}}$ & -2.93 & 0.20 & .004 & -2.53 & 0.15 & .012 & -1.12 & 0.04 & .27 \\
\hline Adiponectin $^{\mathrm{c}}$ & -.67 & 0.04 & .51 & -0.79 & 0.09 & .43 & 0.02 & 0 & .99 \\
\hline Insulin $^{\mathrm{c}}$ & 0.91 & 0.06 & .36 & 0.58 & 0.05 & .56 & 0.93 & 0.19 & .36 \\
\hline Leptin $^{\mathrm{c}}$ & -4.27 & 1.40 & $<.0001$ & -4.10 & 1.83 & $<.0001$ & -2.52 & 1.39 & .012 \\
\hline Glucose $^{c}$ & 1.02 & 0.08 & .31 & 1.96 & 0.37 & .051 & 0.32 & 0.02 & .75 \\
\hline Regression model & & 54.80 & $<.0001$ & & 55.27 & $<.0001$ & & 56.38 & $<.0001$ \\
\hline
\end{tabular}

${ }^{\text {a }}$ The $T$ value is the $t$ test value for testing the hypothesis that the regression coefficient of this particular variable is 0 vs the alternative that it is not, after removing the influence of all other independent variables.

${ }^{\mathrm{b}}$ We show the incremental sequential $R^{2}$, that is, the increase in $R^{2}$ (presented as percentage) when this independent variable was added to those above. Body size and metabolic parameters were introduced taking into account the correlation coefficient with birth weight given in Table 3 . We used baseline BW rather than BMI because of a higher correlation coefficient. Tumor necrosis factor $\alpha$ was not included as a metabolic variable because it failed to correlate with any maternal body size parameter or birth weight (Tables 2 and 3).

${ }^{c}$ We used log-transformed values to obtain normal data distribution or improved normality of data distribution.

separate analysis, they were 2.6 times more likely to have a leptin value in the highest quartile $(>1.44 \mathrm{nmol} / \mathrm{L}$ or $>23 \mathrm{ng} / \mathrm{mL})$; the frequency of hypertension $(34 \% \mathrm{vs} 15 \%$; $\chi^{2}$ test, $\left.P<.0001\right)$, but not smoking $(P=.97)$ or female fetuses $(P=.63)$, was higher in this subgroup. Gravidas with LGA fetuses were more likely to be parous and to carry a boy, compared with those with an AGA fetus, and they were slightly more likely to have a baseline BW of

Table 5

Maternal body size and metabolic parameters in SGA $\left(\mathrm{P}_{1-10}, \mathrm{n}=42\right)$ vs AGA $\left(\mathrm{P}_{11-90}, \mathrm{n}=496\right)$ pregnancies, and in LGA $\left(>\mathrm{P}_{90}, \mathrm{n}=93\right)$ vs AGA pregnancies: multinomial logistic regression

\begin{tabular}{|c|c|c|c|c|}
\hline \multirow[t]{2}{*}{ Dependent variable: birth weight } & \multicolumn{2}{|c|}{ SGA vs AGA (reference group) } & \multicolumn{2}{|l|}{ LGA vs AGA (reference group) } \\
\hline & Odds ratio ( $95 \%$ confidence interval) & Wald $P$ & Odds ratio ( $95 \%$ confidence interval) & Wald $P$ \\
\hline \multicolumn{5}{|l|}{ Independent variables } \\
\hline \multicolumn{5}{|l|}{ General parameters } \\
\hline Gestational age (wk) & $0.90(0.75-1.08)$ & .27 & $0.98(0.84-1.14)$ & .82 \\
\hline Sex (female vs male) & $2.49(1.22-5.04)$ & .012 & $0.55(0.34-0.88)$ & .013 \\
\hline Parity (nulliparous vs parous) & $2.57(1.20-5.51)$ & .015 & $0.41(0.24-0.68)$ & .0006 \\
\hline Smoking (yes vs no) & $5.04(2.00-12.67)$ & .0006 & $0.85(0.33-2.15)$ & .73 \\
\hline Hypertension (yes vs no) & $1.93(0.86-4.31)$ & .11 & $0.83(0.45-1.53)$ & .54 \\
\hline \multicolumn{5}{|l|}{ Maternal body size parameters } \\
\hline Baseline $\mathrm{BW}>63.8$ vs $\leq 63.8 \mathrm{~kg}^{\mathrm{a}}$ & $0.67(0.31-1.44)$ & .31 & $1.75(1.002-3.07)$ & .049 \\
\hline BW change to GCT $>7.2 \mathrm{vs} \leq 7.2 \mathrm{~kg}^{\mathrm{a}}$ & $0.26(0.12-0.55)$ & .0005 & $1.76(1.07-2.87)$ & .025 \\
\hline Height $>167$ vs $\leq 167 \mathrm{~cm}^{\mathrm{a}}$ & $1.53(0.75-3.12)$ & .24 & $1.41(0.86-2.31)$ & .18 \\
\hline \multicolumn{5}{|l|}{ Maternal metabolic markers } \\
\hline sOb-R $>35.7$ vs $\leq 35.7 \mathrm{U} / \mathrm{mL}^{\mathrm{a}}$ & $1.36(0.61-3.03)$ & .46 & $0.79(0.46-1.37)$ & .41 \\
\hline Adiponectin $>0.493$ vs $<0.493 \mathrm{nmol} / \mathrm{L}^{\mathrm{a}}$ & $1.15(0.58-2.28)$ & .68 & $0.88(0.55-1.41)$ & .59 \\
\hline Insulin $>617$ vs $<617 \mathrm{pmol} / \mathrm{L}^{\mathrm{a}}$ & $1.11(0.52-2.37)$ & .79 & $1.39(0.83-2.32)$ & .21 \\
\hline \multicolumn{5}{|l|}{ Leptin } \\
\hline$>1.085 \mathrm{vs}<1.085 \mathrm{nmol} / \mathrm{L}^{\mathrm{a}}$ & $1.93(0.88-4.25)$ & .10 & $0.96(0.55-1.68)$ & .88 \\
\hline$>1.440 \mathrm{vs}<1.440 \mathrm{nmol} / \mathrm{L}^{\mathrm{b}}$ & $2.58(1.05-6.34)$ & .039 & & \\
\hline Glucose $>6.20 \mathrm{vs}<6.20 \mathrm{mmol} / \mathrm{L}^{\mathrm{a}}$ & $0.62(0.29-1.31)$ & .21 & $0.88(0.54-1.45)$ & .62 \\
\hline
\end{tabular}

${ }^{a}$ This value represents the median value.

${ }^{\mathrm{b}}$ Because the above analysis with the median value as the cutoff point showed $P<.15$, we also assessed the $\mathrm{P}_{75}$ leptin value as the cutoff point. The odds ratios and the Wald $P$ levels of the other parameters were similar in this separate analysis (data not shown). 
more than $63.8 \mathrm{~kg}$ and a BW gain of more than $7.2 \mathrm{~kg}$ until the GCT; but the metabolic markers were not different between the LGA and AGA groups.

\section{Discussion}

The current study confirms that birth weight is related to maternal baseline $\mathrm{BW}$ and height, and BW change from baseline to 24 to 29 weeks' GA, yet these parameters explained a modest $7 \%$ of the variance in birth weight. Although insulin, adiponectin, leptin, and sOb-R, measured at the GCT, were also significantly related to birth weight, they did not add meaningfully - from a clinical viewpoint - to birth weight prediction. The analyses were similar when restricted to pregnancies with a normal GCT or to overweight women.

Of the body size parameters, BW change emerged as the most important predictor of birth weight, particularly in gravidas who were overweight at baseline (Table 4). A recent study also showed that the risk of an LGA infant in obese glucose-tolerant women was proportional to gestational BW gain [20]. Interestingly, BW change in the first and second trimester has a stronger influence on birth weight than that in the third trimester [21]. Our data buttress the recommendation by the Institute of Medicine that overweight gravidas should gain less than normal-weight gravidas to avoid the perinatal risks associated with macrosomia. Antenatal clinics that have abolished serial weight measurements may need to reconsider their practice. Baseline BMI was inferior to BW as a correlate of birth weight (Table 3), in line with previous data [1]; hence, we used BW in the multiple regression analyses.

Of the metabolic markers, leptin and sOb-R were the best predictors of birth weight. A plasma leptin value in the highest quartile was more common among gravidas with an SGA fetus, as previously reported [14]. These women were more likely to be hypertensive during pregnancy; indeed, circulating leptin was reported to be elevated in preeclamptic women, even before the clinical onset [22], owing to a robust up-regulation of placental leptin gene expression [23]. Soluble leptin receptor binds and sequesters most of the circulating leptin. The percentage of bound leptin was negatively correlated with fat mass and insulin resistance in men [24]. Here, we confirmed a negative correlation between sOb-R and both insulin and leptin concentrations in pregnant women [5], and we showed for the first time an inverse correlation between sOb-R levels and $\mathrm{BW}$ change during pregnancy.

The post-GCT glucose concentration was not a significant predictor of birth weight in this sample, in agreement with data showing that the incidence of macrosomia was unrelated to the glucose tolerance status of white US gravidas [25]. In 3637 pregnancies without GDM, birth weight of more than $4.0 \mathrm{~kg}$ was related to the maternal fasting as well as the 1- and 2-hour glucose values during an oral glucose tolerance test; but in a multivariate analysis including the BMI, only fasting glucose was retained as a determinant of macrosomia [26]. Even among women with established GDM, prepregnancy BMI and BW gain before diagnosis were stronger predictors of birth weight than was fasting glucose [27].

The study sample consisted of white Belgian gravidas with a single fetus, but was otherwise unselected. The clinical outcome (Table 1) was comparable with the perinatal outcome in Flanders, Belgium, in 2003 [28]. Gestational age, sex, parity, smoking, and hypertension were controlling variables; however, we did not control for other potentially confounding factors such as socioeconomic status, which is a limitation of our analysis. Another limitation is that, although it is a reflection of clinical practice, there was a considerable range in GA at baseline (5-14 weeks) and at the GCT (24-29 weeks). In addition, the measurement of insulin and adipokines both at baseline and at the GCT may improve the predictive power of metabolic markers. Finally, it is possible that other adipokines than those measured in the current study (eg, interleukin 6, resistin) may have a clinical benefit.

The quest for reliable indicators in maternal plasma of fetal growth rate or birth weight has not, so far, been rewarding. Apart from insulin and adipokines, some studies have addressed whether components of the growth hormone axis can predict birth weight, but we [15] and others [29] did not find associations between placental growth hormone, insulin-like growth factor I, or insulin-like growth factorbinding protein 1 concentrations and birth weight. In a longitudinal study, the placental growth hormone curve during pregnancy differed according to the birth weight tertile, but only from 35 weeks' GA [30]. We may, therefore, need to redirect the focus from hormones and metabolic factors to hemodynamics. Older studies demonstrated that plasma volume expansion during pregnancy is strongly correlated with birth weight, probably through a positive effect on uteroplacental blood flow. In a small study, prepregnancy $\mathrm{BW}$ was correlated with baseline plasma volume and, to a lesser extent, with the gestational increment in plasma volume [31]. The relationship between BW change and plasma volume expansion during pregnancy is unknown, but we surmise that the maternal energy status drives plasma volume expansion and uteroplacental blood flow.

In conclusion, measuring insulin and adipokines at the time of the GCT has limited, if any, clinical benefit to improve the prediction of birth weight on the basis of clinical parameters including maternal body size.

\section{Acknowledgment}

This study was supported by grants from the Fonds voor Wetenschappelijk Onderzoek-Vlaanderen (Belgium) (grant G.0221.03) and the Katholieke Universiteit Leuven (Onderzoekstoelage OT/02/48). 


\section{References}

[1] Garn SM, Pesick SD. Relationship between various maternal body mass measures and size of the newborn. Am J Clin Nutr 1982; $36: 664-8$

[2] Abrams B, Altman SL, Pickett KE. Pregnancy weight gain: still controversial. Am J Clin Nutr 2000;71(Suppl):1233S - 41S.

[3] Institute of Medicine. Nutrition during pregnancy. Part I, weight gain. Washington (DC): National Academy Press; 1990.

[4] Niswender KD, Baskin DG, Schwartz MW. Insulin and its evolving partnership with leptin in the hypothalamic control of energy homeostasis. Trends Endocrinol Metab 2004;15:362-9.

[5] Verhaeghe J, van Bree R, Lambin S, et al. Adipokine profile and $\mathrm{C}$-reactive protein in pregnancy: effects of glucose challenge response versus body mass index. J Soc Gynecol Investig 2005;12:330 -4.

[6] Chan JL, Blüher S, Yiannakouris N, et al. Regulation of circulating soluble leptin receptor levels by gender, adiposity, sex steroids, and leptin: observational and interventional studies in humans. Diabetes 2002;51:2105 - 12 .

[7] Catalano PM, Tyzbir ED, Roman NM, et al. Longitudinal changes in insulin release and insulin resistance in non-obese pregnant women. Am J Obstet Gynecol 1991;165:1667-72.

[8] Sattar N, Greer IA, Pirwani I, et al. Leptin levels in pregnancy: marker for fat accumulation and mobilization? Acta Obstet Gynecol Scand 1998;77:278-83.

[9] Lewandowski K, Horn R, O’Callaghan CJ, et al. Free leptin, bound leptin, and soluble leptin receptor in normal and diabetic pregnancies. J Clin Endocrinol Metab 1999;84:300 - 6 .

[10] Chandran M, Phillips SA, Ciaraldi T, et al. Adiponectin: more than just another fat cell hormone? Diabetes Care 2003;26:2442 -50.

[11] Kirwan JP, Hauguel-De Mouzon S, Lepercq J, et al. TNF- $\alpha$ is a predictor of insulin resistance in human pregnancy. Diabetes 2002; $51: 2207-13$

[12] Breschi MC, Seghieri G, Bartolomei G, et al. Relation of birth weight to maternal plasma glucose and insulin concentration during normal pregnancy. Diabetologia 1993;36:1315-21.

[13] Catalano PM, Drago NM, Amini SB. Maternal carbohydrate metabolism and its relationship to fetal growth and body composition. Am J Obstet Gynecol 1995;172:1464-70.

[14] Scholl TO, Stein TP, Smith WK. Leptin and maternal growth during adolescent pregnancy. Am J Clin Nutr 2000;72:1542 - 7 .

[15] Verhaeghe J, Pintiaux A, Van Herck E, et al. Placental GH, IGF-I, IGF-binding protein-1, and leptin during a glucose challenge test in pregnant women: relation with maternal body weight, glucose tolerance, and birth weight. J Clin Endocrinol Metab 2002;87: $2875-82$.

[16] American Diabetes Association. Gestational diabetes mellitus. Diabetes Care 2004;27(Suppl 1):S88-S90.

[17] Verhaeghe J. Gestational diabetes mellitus: pathophysiology, screening and diagnosis, and management. In: Van Assche FA, editor. Diabetes and pregnancy European practice in gynaecology and obstetrics, vol. 7 Amsterdam, The Netherlands: Elsevier B.V.; 2004. p. 15-27.

[18] Davey DA, McGillivray I. The classification and definition of the hypertensive disorders of pregnancy. Am J Obstet Gynecol 1988; 158:892-8.

[19] Devlieger H, Martens G, Bekaert A, et al. Standaarden van geboortegewicht-voor-zwangerschapsduur voor de Vlaamse boreling. Tijdschr Geneeskd 2000;56:1 - 14 [in Dutch].

[20] Jensen DM, Ovesen P, Beck-Nielsen H, et al. Gestational weight gain and pregnancy outcomes in 481 obese glucose-tolerant women. Diabetes Care 2005;28:2118-22.

[21] Brown JE, Murtaugh MA, Jacobs DR, et al. Variation in newborn size according to pregnancy weight change by trimester. Am J Clin Nutr 2002;76:205-9.

[22] Anim-Nyame N, Sooranna SR, Steer PJ, et al. Longitudinal analysis of maternal plasma leptin concentrations during normal pregnancy and pre-eclampsia. Hum Reprod 2000;15:2033 - 6.

[23] Reimer T, Koczan D, Gerber B, et al. Microarray analysis of differentially expressed genes in placental tissue of pre-eclampsia: up-regulation of obesity-related genes. Mol Hum Reprod 2002;8: 674-80.

[24] Sandhofer A, Laimer M, Ebenbichler CF, et al. Soluble leptin receptor and soluble receptor-bound fraction of leptin in the metabolic syndrome. Obes Res 2003;11:760-8.

[25] Saldana TM, Siega-Riz AM, Adair LS, et al. The association between impaired glucose tolerance and birth weight among black and white women in central North Carolina. Diabetes Care 2003;26: 656-61.

[26] Sermer M, Naylor CD, Gare DJ, et al. Impact of increasing carbohydrate intolerance on maternal-fetal outcomes in 3637 women without gestational diabetes: the Toronto Tri-Hospital Gestational Diabetes Project. Am J Obstet Gynecol 1995;173:146-56.

[27] Snyder J, Gray-Donald K, Koski KG. Predictors of infant birth weight in gestational diabetes. Am J Clin Nutr 1994;59:1409-14.

[28] Cammu H, Martens G, De Coen K, et al. Perinatale activiteiten in Vlaanderen 2003. Brussel: vzw Studiecentrum voor Perinatale Epidemiologie; 2004 [in Dutch].

[29] Bhatia S, Faessen GH, Carland G, et al. A longitudinal analysis of maternal serum insulin-like growth factor I (IGF-I) and total and nonphosphorylated IGF-binding protein-1 in human pregnancies complicated by intrauterine growth restriction. J Clin Endocrinol Metab 2002;87:1864-70.

[30] Chellakooty M, Vangsgaard K, Larsen T, et al. A longitudinal study of intrauterine growth and the placental growth hormone $(\mathrm{GH})$-insulinlike growth factor I axis in maternal circulation: associations between placental GH and fetal growth. J Clin Endocrinol Metab 2004; 89:384-91

[31] Gibson HM. Plasma volume and glomerular filtration rate in pregnancy and their relation to differences in fetal growth. J Obstet Gynaecol Br Commonw 1973;80:1067-74. 